\title{
PARTICIPATION PATTERN OF PEOPLE WITH HIV/AIDS IN THE PEER SUPPORT GROUP IN EAST KALIMANTAN
}

\author{
Budi Irwansyah \\ Doctoral Program in Development and Promotion, \\ Sebelas Maret University
}

\begin{abstract}
BACKGROUND: The presence of peer support group is deemed important as it is expected to support people with HIV/AIDS, in terms of emotional, informational, instrumental, and financial support. Empowerment of people with HIV/AIDS may enhance their participation in peer support group. This study aimed to describe participation pattern of people with HIV/AIDS in the peer support group, in East Kalimantan.

SUBJECT AND METHODS: This was a qualitative study using case study approach, carried out in Samarinda, East Kalimantan, from January to August 2015. Key informants were selected purposively, which included people with HIV/AIDS and peer support group management. The data were collected by direct observation, in-depth interview, and focus group discussion. Content analysis was used to analyze qualitative data.

RESULTS: People with HIV/AIDS involved in the peer support group in various phases of activity, including planning, advocacy, monitoring, and using information available at the peer support group to prevent HIV/AIDS transmission and opportunistic infection. There were 2 patterns of support for people with HIV/AIDS: (1) Direct support by nongovernment organization (advocacy and common activities); (2) Indirect support by the government and private sector (provision of facilities, budget fund, and healthy public policy).

CONCLUSION: Support from the government, private sector, and nongovernment organization have shown to enhance participation of people with HIV/AIDS in the peer support group. The government and private sector are suggested to involve people with HIV/AIDS in various peer group activities, such as campaign and health education. The government and the private sector are also suggested to support budget that can be managed by the peer group, and to facilitate creative and productive economic activities that support independence of people with HIV/AIDS.
\end{abstract}

Keywords: people with HIV/AIDS, empowerment, peer support group, government, private sector 